\title{
Methods for Reducing Violence in Schools: A Systematic Review
}

\author{
Don R. Kelly ${ }^{1}$ \\ ${ }^{1}$ School of Social Work, University of Texas Arlington, Arlington, Texas, USA \\ Correspondence: Don R. Kelly, School of Social Work, University of Texas Arlington, Arlington, Texas, USA. \\ Tel: 1-575-571-6849. E-mail: don.kelly@uta.edu
}

Received: December 13, 2016

doi:10.5539/jedp.v7n1p200

\author{
Accepted: January 20, 2017 Online Published: February 15, 2017 \\ URL: http://doi.org/10.5539/jedp.v7n1p200
}

\begin{abstract}
This systematic review examines programs designed to reduce school violence. The review indicates the lack of definitive results of previous reviews, addresses the gaps in the existing literature, and supports the need for social workers to play an active role in organizing, promoting, and coordinating violence reduction processes. In addition, the review attempts to clarify the effects of violence reduction processes as they relate to school culture change.

Results indicate that programs identified in this systematic review could help to create positive social environments that reduce incidences of violence creating and atmosphere more favorable to learning. Further, identified programs are shown to reduce office referrals, in school suspensions, and out of school suspensions. While these results are notable, it is likely the identified programs are one component of a holistic strategy for changing school culture. Adding other processes could help to sustain a positive social environment over time and reduce incidence of violence, office referrals, and suspensions. Further study is needed to substantiate this hypothesis as this is beyond this study.
\end{abstract}

Keywords: violence reduction, school violence reduction, school suspension reduction, violence reduction interventions, alternatives to suspension, restorative justice, peer involvement, behavior modification, conflict resolution

\section{Introduction}

\subsection{Rational}

The Columbine High School shooting that occurred on April 20, 1999 had a ripple effect across the United States. Since the Columbine massacre schools across the United States have responded with an energized effort to safeguard schools (Heinen, Webb-Dempsey, Moore, McClellan, \& Friebel, 2007). These efforts are commendable; however, according to Grisham, Deutsch, and Durando (2014), there have been no less than five mass shootings in elementary and high school settings since Columbine. Mass shootings are defined as having four or more victims. The most notable mass shootings include:

- March 5, 2001, Santana High School, the offender opened fire inside the Santee, Calif. High school, killed two students, and injured 13 others.

- March 21, 2005, Red Lake Senior High School, the shooter kills his grandfather and a companion of his grandfather's, and then heads to a high school on the Red Lake Indian Reservation in Minnesota killing five students, a teacher, and a security guard before taking his own life.

- Feb. 27, 2012, Chardon High School, three students are killed after the shooter opens fire inside the cafeteria of the Chardon, Ohio, school.

- Dec. 14, 2012, Sandy Hook Elementary School, the offender shoots and kills his mother in their home before driving to Sandy Hook Elementary in Newtown, Conn. He kills 26 people at the school, 20 of whom are first-graders, before shooting and killing himself.

- Oct. 24, 2014, Marysville Pilchuck High School, two people, including a gunman who opens fire on fellow students are dead at a high school north of Seattle. 
While many schools focus on security utilizing surveillance, metal detectors, and increased police presence, others have suggested that schools should focus on the impact of school culture (Mattaini \& McGuire, 2006; Heinen et al., 2007; Coyle, 2008; Bosworth \& Judkins, 2014). Creating safe school environments using security techniques help students and faculty feel safe; however, these techniques do little to change the environment that cultivates violent behavior (May, 2014). Further, utilization of punitive measures such as suspensions and loss of privileges may stifle misbehavior in the immediate context; yet, long-term change is small (Chin, Dowdy, Jimerson, \& Rime, 2012; Mullet, 2014). According to Mullet (2014), teaching prosocial behaviors, and motivating healthier decision making in the misbehaving students is the key.

Whitted and Dupper (2005) indicate that violence manifests itself in numerous ways. Growing evidence underlying forms of violence such as bullying have a profound effect on the learning environment of the school, and if left unchecked, can lead to more serious forms of violence (Whitted \& Dupper, 2005). Preventing low-level forms of violence like bullying requires a comprehensive approach that includes a focus on school climate (Bosworth \& Judkins, 2014). Sharkey and Fenning (2012) indicate that punitive measures are ineffective in teaching proactive behaviors and may have the opposite effect of exacerbating undesirable behaviors.

According to Boyd and Anderson (2013), three paradigms are utilized when determining levels of behavioral interventions. Universal (Tier I) interventions are designed to promote pro-social behavior among all students (Boyd \& Anderson, 2013). Targeted (Tier II) interventions are intended for students at risk for developing serious problematic behavior and intensive (Tier III) interventions are aim to support students who engage in serious challenging behavior that has not responded to other efforts (Boyd \& Anderson, 2013).

Understanding that numerous programs work to reduce violence in schools, this study seeks to answer three questions regarding interventions and methodologies. What are the interventions being used? What interventions seem most effective? What are the research features of the more successful studies? Further, the study sought to identify the general target of the interventions, their measurement of outcomes, and other defining features such as theoretical base and types of assessment tools.

\subsection{Objective}

As mentioned, this study seeks to identify leading interventions designed to reduce school violence. Further, the study seeks to understand what the interventions try to change, their contribution to overall culture change, the feasibility of generalization to other demographics, methodology, and sample acquisition. As there are is a lack of definitive results in previous reviews, this study seeks to address these gaps in the existing literature. This study identifies the need for social workers to play an active role in organizing, promoting, and coordinating violence reduction processes, identify processes that promote change in school culture, their efficacy, and the role of social workers in sustaining cultural change. While each of the identified interventions show positive results, none appears capable of eliminating violent behavior $100 \%$.

\section{Methods}

In formulating the scope of the review of reviews, the participants, interventions, comparators, outcomes, and study design are considered. A systematic search strategy was established before commencing the literature search to ensure that the systematic review was comprehensive, thorough, and objective. Search terms included the setting (middle school*, OR high school*), the problem (disorder*, OR violence, OR discipline, OR behavior*), and interventions (alternatives to suspension*, OR school violence prevention, OR violence reduction*, OR violence reduction programs, OR teacher training*, OR restorative justice, OR peer involvement, OR behavior modification*, OR conflict resolution*). In addition, only articles published after the events of the Columbine school shooting on April 20, 1999 were included. To guard against bias, two reviewers must have agreed that the article was fit for inclusion both at initial screening and at full text review.

\subsection{Eligibility Criteria}

Selected criteria helped to narrow the focus of the study with an emphasis on prevention for those at-risk (selective interventions) and treatment (indicated interventions), which included mentoring as the intervention or one component of the intervention. The study included psychotherapy, behavior modification, and cognitive behavioral interventions that embraced helping services as part of a professional role. Experimental and quasi-experimental designs were included. Further, the review was limited to studies conducted within the United States, as resources for translating reports not reported in English were limited. Eligibility criteria included eleven items: 1) articles published between April 1999 through May 2015; 2) written in English, full-text; 3) in primary and secondary education; 4) children ages 12 years to 17 years; 5) empirical studies; 6) 
study sample greater than 3; 7) not a case study; 8) independent studies; 9) reviews of violence reduction methods; 10) not race or gender specific; and 11) study addressed intervention outcomes.

\subsection{Search}

The study search integrated various databases including EBSCO-Criminal Justice Abstracts with Full Text, Education Abstracts (H. W. Wilson), ERIC, Legal Collection, MEDLINE, PsycARTICLES, Psychology and Behavioral Sciences Collection, PsycINFO, Educational Administration Abstracts, The Campbell Collaboration Library of Systematic Reviews, ProQuest Dissertations and Theses Global (PQDT Global), Doctoral Dissertations, and Google Scholar. Finally, the reference lists of primary studies and reviews in the studies identified from the search of electronic resources were scanned for unidentified studies that related to the systematic review. The same keywords were utilized for all search engines.

\subsection{Data Extraction}

Only English articles were selected because English was the primary language of the reviewers. Only articles published from December 1999 through August 2015 were utilized as date specific articles were sought to emphasize programs developed to reduce school violence since the Columbine school shooting. The main thrust of the investigation focused on primary and secondary education setting targeting violence intervention programs, concentrating on children ages 12 years to 17 years. This was important because the preschool and college setting was not the object of the study.

Empirical quantitative studies were selected to give the review stronger credibility using study samples of three or greater. The researcher was not interested in case studies, these type studies could not be generalized. For clarity, the researcher sought independent study and not multiple papers from the same research project. Further, articles had to include reviews of violence reduction methods, not race or gender specific, and must have addressed intervention outcomes that were student, or school-based.

\section{Results}

\subsection{Study Selection}

The data collection process yielded 2304 references. A title review found 746 studies that were not relevant including 127 Mendeley software duplicates, which were removed from consideration yielding a final sample of 1558 studies suitable for abstract screening. Of the 1558 studies, 1019 studies were excluded after abstract review because they were not relevant. After the initial screening process, 539 were selected for full text review. After full text review, 520 did not meet selection criteria of which 76 studies were reviewed by four reviewers. The final consensus yielded a final sample of 19 studies. Studies were eliminated from consideration at full text review because they were not empirical $(n=23,4 \%)$, not peer reviewed $(n=9,2 \%)$, a case study $(n=18,8 \%)$, studied the wrong population $(n=62,12 \%)$, specific to teachers only $(n=38,7 \%)$, not relevant $(n=43,8 \%)$, conducted in the wrong setting $(\mathrm{n}=47,9 \%)$, were the wrong study design [qualitative] $(\mathrm{n}=14,3 \%)$, had the wrong intervention [not a violence reduction intervention] $(\mathrm{n}=64,13 \%)$, had the wrong outcome [reduce absences, smoking, drug use] $(\mathrm{n}=99,20 \%)$, were mental health studies $(\mathrm{n}=53,11 \%)$, were disability studies $(\mathrm{n}=12,2 \%)$, or had an inadequate sample ( $\mathrm{n}=7,1 \%)$. All included studies were produced between April 1999 and May 2015.

\subsection{Study Characteristics}

Nineteen studies were selected for the review and contained characteristics for inclusion. Thirteen studies were quasi-experimental, three studies were experimental, one study was exploratory, one study was descriptive, and one study utilized a mixed methods approach. Fourteen studies included multiple schools, four studies utilized one school, and one study used school helping professionals. The included studies involved 287,936 participants.

The selected study samples had a range of demographic characteristics. Most samples comprised a mix of boys and girls with one sample focusing only on boys. Minority children were well represented with most studies having primarily minority youth. Represented school ages ranged from 12 to 17 in primary through secondary education settings. A range of risk levels was also present, from general population students to students already exhibiting aggressive behavior. Several of studies selected youth that demonstrated aggressive or violent behavior. The majority of the studies utilized non-random convenience sampling with samples collected involving as many as 107 schools to as few as one school representing elementary, middle, and high schools. One study focused entirely on three Native American school districts. Sample sizes ranged from 3 to 110,000 students and 46 to 2400 teachers. One study collected data from 762 school social workers, psychologist, 
counselors, and psychology interns. Mostly, samples were collected based on availability and willingness to participate.

All study designs assessed interventions for at least one outcome representing either 1) aggressive or violent behavior (e.g., fighting, bullying); 2) disruptive behavior (e.g., behavior problems, conduct disorder); or 3) problem behavior (i.e., internalizing and/or externalizing problems). Most studies applied a quasi-experimental design that compared students exposed to one or more identifiable interventions with one or more control or comparison conditions on at least one outcome. Quasi-experimental studies were most likely to predominate due to feasibility and the ethical responsibilities associated with an at risk population such as children. Those participants not randomly assigned were involved with a pretest and a posttest on at least one qualifying outcome or sufficient demographic for equivalence of the treatment and control groups.

Measurement of outcomes in the selected studies employed a heterogeneous mix of standardized scales. Heterogeneity of scales did not seem to be a problem as most studies exhibited adequate fidelity of intervention effectiveness. The majority of studies sought to reduce incidences of office discipline referrals, suspensions, and problem behavior. Each of the selected studies utilized various standardized tools that were unique to the intervention being utilized. SWPBIS and SS/HS interventions mostly employed the School-wide Evaluation Tool (SET) and the Teacher Observation of Classroom Behavior Checklist (TOCA) (Boyd \& Anderson, 2013; Flannery, Fenning, Kato, \& McIntosh, 2014; Harris, McFarland, Siebold, Aguilar, \& Sarmiento, 2007; Sprague, Nishioka, \& Smith, 2007). OBPP used the Olweus Bully Questionnaire (Black \& Washington, 2008; Schroeder et al., 2012), and CRE interventions applied the Behavior Assessment Scale (teachers \& students) and the Teen conflict Survey (Scheckner \& Rollin, 2003; Smith, Daunic, Miller, \& Robinson, 2002). These instruments were not used exclusively by these interventions; all of the studies used a wide variety of survey instruments.

According to Flannery, Fenning, Kato, and McIntosh (2014), the SET comprises 28 items distributed into seven subscales measuring whether schools have implemented the essential features of SWPBIS. The TOCA is a nonclinical measure of children's behavior completed by teachers to assess the impact of school-based preventive interventions on teacher's ratings of children's behavior (Bradshaw \& Waasdorp, 2015). The OBQ is a 42 item multipart questionnaire that identifies data on bullying problems, attitudes regarding bullying, bystander perceptions of bullying, and general satisfaction with school (Schroeder et al., 2012). The Behavior Assessment Scale is a 109 item pre-intervention tool that measures level of aggression, social skills, problem internalization, and school problems (Scheckner \& Rollin, 2003). Finally, the Teen Conflict Survey is a 41-item Likert scale tool that obtains information regarding the participants' demographic and environmental histories. Only the SET, TOCA, and Behavior Assessment Scale were used with multiple intervention programs such as SWPBIS, SS/HS, and CRE.

It should be mentioned that besides the scales and surveys applied in the selected studies, many of the studies also collected school data related to office disciplinary referrals and suspensions. Most interesting is that only one study collected data related to academic results and only one study collected data related to attendance. Considering that academic achievement could be the ultimate goal of any primary or secondary institution, a reasonable person would hope that by reducing violence academic achievement could be maximized. Yet this was a priority in only one study.

Of the included studies, various programs were utilized as interventions for violence reduction in primary and secondary education. Three studies applied the Olweus Bullying Prevention; six studies employed Schoolwide Positive Behavior Intervention and Support; three studies utilized the Safe Schools/Healthy Students; and three schools made use of the Conflict Resolution/Peer Mediation programs. Additionally, one study each utilized Breaks are Better, Solution Focused Therapy, Skill Based Violence Prevention, Too Good for Violence, DARE Plus, Bully Proofing Your School, Students Managing Anger Together, and Positive Behavior Support/Peer Assisted Learning programs were used respectively. Of the included studies, five indicated a reduction in disciplinary referrals, four reported reductions in bullying, seven reported reductions in problem behavior, two studies reported increased use of conflict resolution skills, and one reported students feeling safer.

Of the nineteen selected studies, four intervention programs were prominently used to reduce violence in schools. Six of the included studies identified Schoolwide Positive Behavior Intervention and Support (SWPBIS) as an intervention approach. The SWPBIS program refers to a systems change process for an entire school or district (Boyd \& Anderson, 2013; Bradshaw, Waasdorp, \& Leaf, 2015; Flannery, Fenning, Kato, \& McIntosh, 2014; Nocera, Whitbread, \& Nocera, 2014; Sorlie, \& Ogden, 2007). The underlying theme is teaching behavioral expectations in the same manner as any core curriculum subject (Nocera, Whitbread, \& Nocera, 2014). The 
school focuses on three to five behavioral expectations that could include respect for yourself, others, property, relationships, responsibilities, or safety (Sorlie \& Ogden, 2007).

Three studies identified the Olweus Bullying Prevention Program (OBPP) as the intervention method. The OBPP is designed to improve peer relations and make schools safer, provide more positive places for students to learn, and reduce existing bullying problems among students (Black \& Washington, 2008; Lund, Blake, Ewing, \& Banks, 2012; Menard \& Grotpeter, 2014; Schroeder, Messina, Schroeder, Good, Barto, Saylor, \& Masiello, 2012). Three studies identified Safe Schools/Healthy Schools (SS/HS) as a mode of intervention and three studies identified Conflict Resolution Education (CRE) as a technique for reducing violence.

The SS/HS program works to prevent youth violence and substance use in schools and communities, and promotes and improves student access to mental health services (Harris, McFarland, Siebold, Aguilar, \& Sarmiento, 2007; Massey, Boroughs, \& Armstrong, 2007; Sprague, Nishioka, \& Smith, 2007). The program recognizes that schools alone cannot respond effectively to violence, substance use, untreated mental illness, and a broad range of antisocial behaviors (Massey, Boroughs, \& Armstrong, 2007). Therefore, SS/HS works to strengthen the role of schools as healthy learning environments that support the academic, social, and emotional growth of students in a collaborative approach among schools and other youth-serving organizations in the community (Sprague, Nishioka, \& Smith, 2007).

The CRE program includes various interventions in areas such as peer mediation, violence prevention, social and emotional learning, conflict resolution education, and anti-bias education. The strategies mentioned above empower students to deal constructively with interpersonal conflicts, cultural differences, and the need for these approaches to be grounded in day-to-day experiences (Scheckner \& Rollin, 2003; Smith, Daunic, Miller, \& Robinson, 2002; Thompkins, Chauveron, Harel, \& Perkins, 2014). When youth experience success with negotiation, mediation, or consensus decision-making in school they are more likely to use conflict resolution processes elsewhere in their lives (Thompkins, Chauveron, Harel, \& Perkins, 2014).

\subsection{Outcomes}

The systematic review shows that school-based violence reduction programs are often effective, and that particular program elements were associated with a decrease in victimization. It is concluded that, on average, victimization decreased when implementing any of the programs in the selected studies. Outcome results tended to be greater in programs that addressed more than one area such as safety, relationship restoration, conflict resolution skills, and mental health services in some combination. The most important program elements associated with a decrease victimization were programs that included all stakeholder systems such as administration, faculty, students, parents, and the community that incorporated a culture of care philosophy.

Each of the studies acquired samples from readily available school district sources. Each study showed reductions in offices referrals, suspensions, bullying reduction, increased feelings of safety, reduced absenteeism, or increased academic achievement depending on the study objective. Further, various Likert scale questionnaires, surveys, or school reporting records were utilized to collect data depending on the preference of the study researchers. The selected studies used various design techniques such as quasi-experimental (12), experimental (4), exploratory (2), and one mixed study.

Future studies should explore the potential utility of conducting multilevel research combining culture change strategy, CRE (Tier I) SWPBIS and/or OBPP (Tier II), and SS/HS (tier III) interventions as a means of reducing violence, reports of violence, suspension reduction, absenteeism, in comparison to academic achievement. Additionally, more research is needed to determine effectiveness across cultures, gender, race, and higher education.

\section{Discussion}

This study offers a collective look at the programs that help reduce violence in primary and secondary school settings in the United States. The evidence indicates that various strategies are used by professionals such as social workers, psychologist, and counselors to address bullying and victimization in schools. Preliminary findings suggest that collaboration and funding is a strong component in program success and sustainability and intervention systems can assist schools in allocating resources to student need. While the programs mentioned in the selected studies indicate that each intervention can have an effect in reducing Office Disciplinary Referrals (ODR), they also show effectiveness in producing prosocial changes that reduce violence. This should be view with caution as some programs are more widely used and have been tested while others presumably have not been tested extensively. As shown in Table 1, programs with strong evidence are the Olweus Bully Prevention 
Program (OBPP); Schoolwide Positive Behavior Interventions \& Support (SWPBIS); Safe Schools Healthy Students (SS/HS); Violence Prevention Project (VPP); and the Conflict Resolution Peer Mediation (CR/PM) interventions. Programs with limited research or weak evidence include Breaks are Better (BrB); Solutions Focused Therapy (SFT); Skill Based Violence Prevention Program; Too Good for Violence Prevention Program (TGFV); D.A.R.E Plus; Bully-Proofing your School (BPYS); and Students Managing Anger Resolution Together (SMART). All the selected studies show evidence of effectiveness in reducing violence and antisocial behaviors, demonstrate reduction in problem behavior, and are effective alternatives to punitive, reactive policies. Further, interventions in the studies appear to enhance positive behavior and help to establish the schools as warm, welcoming, and safe.

Table1. Intervention rating chart

\begin{tabular}{ll}
\hline \multicolumn{1}{c}{ Intervention } & Evidence \\
\hline Olweus Bully Prevention Program (OBPP) & Strong/Positive \\
Schoolwide Positive Behavior Interventions \& Support (SWPBIS) & Strong/Positive \\
Safe Schools Healthy Students (SS/HS) & Strong/Positive \\
Conflict Resolution Peer Mediation (CR/PM) & Strong/Positive \\
Skill Based Violence Prevention Program (VPP) & Strong/Positive \\
Solutions Focused Therapy (SFT) & Limited Research/Weak \\
Breaks are Better (BrB) & Limited Research/Weak \\
Skill Based Violence Prevention Program & Limited Research/Weak \\
Too Good for Violence Prevention Program (TGFV) & Limited Research/Weak \\
D.A.R.E Plus & Limited Research/Weak \\
Bully-Proofing Your School (BPYS) & Limited Research/Weak \\
Students Managing Anger Resolution Together (SMART) & Limited Research/Weak \\
\hline
\end{tabular}

As this systematic review would suggest, numerous programs work to reduce violence in schools. While all identified programs target problem behaviors and are components to school climate change, none of the interventions appears to address problem behavior at all levels. Many programs seek to educate children in socially acceptable behavior; yet, they do not provide protocols for helping children to change poor behavior. Further, many programs encourage culture change without including all community stakeholders.

The effectiveness that prevention programs have on violent behavior is noteworthy. Across the nineteen studies varying in length, location, implementation, and participants, the interventions increased the participant's awareness of violence and reduced violence in the study environments. Behavior change is important for addressing violence and helping schools establish healthy and safe school environments. An examination of how programs may change behaviors, especially given this is the ultimate goal of many prevention efforts, extends practice knowledge, and broadens understanding of what works to reduce violent behavior. As theories of behavior change indicate that changing attitudes will likely not be enough to lead to changes in actual behaviors and if the goal of prevention programs is to alter behaviors the programs such as those mentioned in this study appear to be on the right track. While an aim of this review was to examine if prevention programs could be effective in reducing violence in schools it does not determine future reductions in victimization behaviors. As the programs in this study appear to be effective at reducing violence, it is likely these programs are only one component of creating and overall change in school culture. It is reasonable to assume that a more holistic approach addressing school culture, behavioral modification for students, social work student counseling, and student involvement to resolve problems in conjunction with programs in this study would have a greater influence in reducing school violence. The results of this study indicated that while prevention programs show promise in decreasing violence, more research is needed.

Limited research investigating the use of multiple interventions of violence reduction in schools was found during this study. Determining the leading interventions in practice is a key contribution. In this systematic review, numerous studies were found that examined the effectiveness programs. Hence, this systematic review 
provides a comparative analysis of these programs advancing knowledge and informing school social workers of multiple approaches effective in reducing school violence. Further, while each of the identified interventions is shown to have a singular positive impact, each intervention appears to address violence reduction through education, active student participation, behavioral intervention, mental health services, parent involvement, and/or community involvement. As a lack of literature addresses holistic approaches addressing all of these areas simultaneously, this study advances knowledge and informs school social work practice by deducing that such an approach could work to maximize culture change and reduce violence in schools.

\subsection{Limitations}

Many studies do not report effect size making it difficult to determine the magnitude of change. Nevertheless, outcome measures used in these studies indicate that positive outcomes were observed. Further, there are problems with fidelity and generalization in many of the studies. It was observed that those responsible for program implementation were often under trained, were not supportive, or unmotivated. This created a problem with consistency and made it unlikely that many results could be generalized. Yet, success in reducing Tier I, II and III levels of violence was evident in most studies; however, no study demonstrated elimination of violent behavior entirely. Additionally, as many studies were non-experimental and non-random, it would be difficult to generalize the results to all school districts in the United States or school systems in other countries. This is not surprising as experimental longitudinal studies can be time consuming, costly, and requires a level of discipline and control that may be too difficult for untrained school personnel.

\section{Conclusions}

This systematic review examines programs designed to reduce school violence. The researcher indicates the lack studies and explains how the present systematic review addresses the gaps in the existing literature on school violence prevention and the need for social workers to play an active role in organizing, promoting, and coordinating violence reduction processes. Mainly, the study seeks to identify the violence reduction processes that promote change in school culture and the role of social workers in sustaining cultural change.

School violence programs were generally effective at reducing the more common types of aggressive behavior seen in schools including fighting, intimidation, and other negative interpersonal behaviors, especially among higher risk students. It is unknown if interventions like those in this study would be effective in preventing severe incidents of school violence committed by very unstable youth.

Long-term research on the effectiveness of these programs in conjunction with other strategies is needed. The main policy implication of our review is holistic school-based programs approaches to reduce violence. Holistic new programs should be designed and tested based on what is most effective.

\section{References}

Black, S., \& Washington, E. (2008). Evaluation of the Olweus Bullying Prevention Program in Nine Urban Schools: Effective Practices and next Steps. ERS Spectrum, 26(4), 7-19. Retrieved from http://search.ebscohost.com/login.aspx?direct=true\&db=eric\&AN=EJ869856\&site=ehost-live

Bosworth, K., \& Judkins, M. (2014). Tapping into the power of school climate to prevent bullying: One application of schoolwide positive behavior interventions and supports. Theory Into Practice, 53(4), 300-307. https://doi.org/10.1080/00405841.2014.947224

Boyd, R. J., \& Anderson, C. M. (2013). Breaks Are Better: A Tier II Social Behavior Intervention. Journal of Behavioral Education, 22(4), 348-365. https://doi.org/10.1007/s10864-013-9184-2

Bradshaw, C. P., Waasdorp, T. E., \& Leaf, P. J. (2015). Examining Variation in the Impact of School-Wide Positive Behavioral Interventions and Supports: Findings from a Randomized Controlled Effectiveness Trial. Journal of Educational Psychology, 107(2), 546-557. https://doi.org/10.1037/a0037630

Chin, J. K., Dowdy, E., Jimerson, S. R., \& Rime, W. J. (2012). Alternatives to suspensions: Rationale and $\begin{array}{llll}\text { recommendations. Journal of School } & \text { Violence, } & 11(2),\end{array}$ https://doi.org/10.1080/15388220.2012.652912

Corcoran, J., \& Gingerich, W. (2009, June 13). The effectiveness of solution-focused therapy. Campbell Systematic Reviews. Retrieved from http://www.campbellcollaboration.org/lib/project/86/

Coyle, H. E. (2008). School culture benchmarks: Bridges and barriers to successful bullying prevention program implementation. Journal of School Violence, 7(2), 105-122. https://doi.org/10.1300/J202v07n02_07 
de Anda, D. (1999). Project Peace: The Evaluation of a Skill-Based Violence Prevention Program for High School Adolescents. Children \& Schools, 21(3), 137-149. https://doi.org/10.1093/cs/21.3.137

Flannery, K. B., Fenning, P., Kato, M. M., \& McIntosh, K. (2014). Effects of School-Wide Positive Behavioral Interventions and Supports and Fidelity of Implementation on Problem Behavior in High Schools. School Psychology Quarterly, 29(2), 111-124. https://doi.org/10.1037/spq0000039

Grisham, L., Deutsch, L., \& Durando, J. (2014). Timeline: Deadly school shootings since Columbine. Retrieved from http://www.usatoday.com/story/news/nation-now/2014/04/19/school-shootings-timeline/7903671/

Hall, B. W., \& Bacon, T. P. (2005). Building a Foundation against Violence: Impact of a School-Based Prevention Program on Elementary Students. Journal of School Violence, 4(4), 63-83. https://doi.org/10.1300/J202v04n04_05

Harris, E., McFarland, J., Siebold, W., Aguilar, R., \& Sarmiento, A. (2007). Universal prevention program outcomes: Safe schools healthy students in a rural, multicultural setting. Journal of School Violence, 6(2), 75-91. https://doi.org/10.1300/J202v06n02_05

Heinen, E., Webb-Dempsey, J., Moore, L., McClellan, C., \& Friebel, C. (2007). Safety matters: How one district addressed safety concerns. Journal of School Violence, 6(3), 113-130. https://doi.org/10.1300/J202v06n03_07

Kelly, M. S., Frey, A., Thompson, A., Klemp, H., Alvarez, M., \& Berzin, S. C. (2016). Assessing the national school social work practice model: Findings from the second national school social work survey. Social Work, 61(1), 17-28. https://doi.org/10.1093/sw/swv044

Komro, K. A., Perry, C. L., Veblen-Mortenson, S., Stigler, M. H., Bosma, L. M., Munson, K. A., \& Farbakhsh, K. (2004). Violence-Related Outcomes of the D.A.R.E. Plus Project. Health Education \& Behavior, 31(3), 335-354. https://doi.org/10.1177/1090198104263337

Lund, E. M., Blake, J. J., Ewing, H. K., \& Banks, C. S. (2012). School counselors' and school psychologists' bullying prevention and intervention strategies: A look into real-world practices. Journal of School Violence, 11(3), 246-265. https://doi.org/10.1080/15388220.2012.682005

Massey, O. T., Boroughs, M., \& Armstrong, K. H. (2007). School violence interventions in the safe schools/healthy students initiative: Evaluation of two early intervention programs. Journal of School Violence, 6(2), 57-74. https://doi.org/10.1300/J202v06n02_04

May, D. C. (2014). School safety in the United States: A reasoned look at the rhetoric. Durham, North Carolina: Carolina Academic Press.

Mattaini, M. A., \& McGuire, M. S. (2006). Behavioral strategies for constructing nonviolent cultures with youth: A review. Behavior Modification, 30(2), 184-224. https://doi.org/10.1177/0145445503259390

Menard, S., \& Grotpeter, K. J. (2014). Evaluation of bully-proofing your school as an elementary school antibullying intervention. Journal of School Violence, 13(2), 188-209. https://doi.org/10.1080/15388220.2013.840641

Moher, D., Liberati, A., Tetzlaff, J., Altman, D. G., \& The PRISMA Group. (2009). Preferred Reporting Items for Systematic Reviews and Meta-Analyses: The PRISMA Statement. PLoS Med, 6(6), e1000097. https://doi.org/10.1371/journal.pmed.1000097

Mullet, J. H. (2014). Restorative discipline: From getting even to getting well. Children \& Schools, 36(3), 157-162. https://doi.org/10.1093/cs/cdu011

Nocera, E. J., Whitbread, K. M., \& Nocera, G. P. (2014). Impact of School-Wide Positive Behavior Supports on Student Behavior in the Middle Grades. RMLE Online: Research in Middle Level Education, 37(8), 1-14. https://doi.org/10.1080/19404476.2014.11462111

Scheckner, S. B., \& Rollin, S. A. (2003). An Elementary School Violence Prevention Program. Journal of School Violence, 2(4), 3-42. https://doi.org/10.1300/J202v02n04_02

Schroeder, B. A., Messina, A., Schroeder, D., Good, K., Barto, S., Saylor, J., \& Masiello, M. (2012). The implementation of a statewide bullying prevention program: Preliminary findings from the field and the importance of coalitions. Health Promotion Practice, 13(4), 489-495. https://doi.org/10.1177/1524839910386887 
Sharkey, J. D., \& Fenning, P. A. (2012). Rationale for designing school contexts in support of proactive discipline. Journal of School Violence, 11(2), 95-104. https://doi.org/10.1080/15388220.2012.646641

Smith, S. W., Daunic, A. P., Miller, M. D., \& Robinson, T. R. (2002). Conflict Resolution and Peer Mediation in Middle Schools: Extending the Process and Outcome Knowledge Base. The Journal of Social Psychology, 142(5), 567-586. https://doi.org/10.1080/00224540209603919

Sorlie, M. A., \& Ogden, T. (2007). Immediate Impacts of PALS: A School-Wide Multi-Level Programme Targeting Behaviour Problems in Elementary School. Scandinavian Journal of Educational Research, 51(5), 471-492. https://doi.org/10.1080/00313830701576581

Sprague, J., Nishioka, V., \& Smith, S. G. (2007). Safe schools, positive behavior supports, and mental health supports: Lessons learned from three safe schools/healthy students communities. Journal of School Violence, 6(2), 93-115. https://doi.org/10.1300/J202v06n02_06

Thompkins, A., Chauveron, L., Harel, O., \& Perkins, D. (2014). Optimizing violence prevention programs: An examination of program effectiveness among urban high school students. Journal of School Health, 84(7), 435-443. https://doi.org/10.1111/josh.12171

Whitted, K. S., \& Dupper, D. R. (2005). Best practices for preventing or reducing bullying in schools. Children \& Schools, 27(3), 167-175. https://doi.org/10.1093/cs/27.3.167

\section{Appendix}

Table 2. Intervention support chart

\begin{tabular}{|c|c|c|c|c|c|c|c|c|}
\hline Author(s) & Yr. & $\mathbf{N}$ & Study Outcome & Intervention & $\begin{array}{l}\text { Study } \\
\text { Design }\end{array}$ & $\begin{array}{l}\text { Tier } \\
\text { Level }\end{array}$ & Change Type & $\begin{array}{l}\text { Variable } \\
\text { Strength }\end{array}$ \\
\hline Black \& Washington & 08 & $\begin{array}{c}13 \text { Schools } 10,269 \\
\text { Students }\end{array}$ & $\begin{array}{l}\text { Reduction Bullying } \\
\text { Events }\end{array}$ & $\begin{array}{c}\text { Olweus Bully } \\
\text { Prevention Program } \\
\text { (OBPP) }\end{array}$ & Quasi & I \& II & Behavior & Reliability \\
\hline Boyd \& Anderson & 13 & $\begin{array}{l}1 \text { School } \\
3 \text { Student }\end{array}$ & $\begin{array}{l}\text { Reduction in Office } \\
\text { Discipline Referrals } \\
\text { (ODRs) }\end{array}$ & Breaks are Better $(\mathrm{BrB})$ & Quasi & III & Behavior & $\begin{array}{c}\text { Reliability } \\
\text { Quality }\end{array}$ \\
\hline $\begin{array}{l}\text { Bradshaw \& } \\
\text { Waasdorp }\end{array}$ & 15 & $\begin{array}{c}37 \text { Schools } \\
\text { 11,738 Students }\end{array}$ & Reduction ODRs & $\begin{array}{l}\text { Schoolwide Positive } \\
\text { Behavior Interventions } \\
\text { \& Support (SWPBIS) }\end{array}$ & Quasi & I \& II & System & $\begin{array}{c}\text { Reliability } \\
\text { Quality } \\
\text { Validity }\end{array}$ \\
\hline $\begin{array}{l}\text { Corcoran \& } \\
\text { Gingerich }\end{array}$ & 13 & $\begin{array}{c}1 \text { District } \\
136 \text { Students }\end{array}$ & Reduction in Impulsivity & $\begin{array}{c}\text { Solutions Focused } \\
\text { Therapy (SFT) }\end{array}$ & Quasi & II \& III & Skills & $\begin{array}{c}\text { Not } \\
\text { Determined }\end{array}$ \\
\hline de Anda & 99 & $\begin{array}{c}1 \mathrm{HS} \\
157 \text { Students }\end{array}$ & Feelings of Safety & $\begin{array}{l}\text { Skill Based Violence } \\
\text { Prevention Program }\end{array}$ & Quasi & I \& II & Skills & Reliability \\
\hline $\begin{array}{l}\text { Flannery, Fenning, } \\
\text { Kato, \& McIntosh }\end{array}$ & 14 & $\begin{array}{c}12 \text { HS } \\
36,653 \text { Students }\end{array}$ & Reduction ODRs & SWPBIS & Quasi & I \& II & System & $\begin{array}{c}\text { Reliability } \\
\text { Validity }\end{array}$ \\
\hline Hall \& Bacon & 05 & $\begin{array}{c}10 \text { Elem. Schools } \\
46 \text { Faculty } \\
999\end{array}$ & $\begin{array}{c}\text { Enhanced } \\
\text { Communication Skills }\end{array}$ & $\begin{array}{c}\text { Too Good for Violence } \\
\text { Prevention Program } \\
\text { (TGFV) }\end{array}$ & Expr. & I \& II & Skills & $\begin{array}{c}\text { Reliability } \\
\text { Quality }\end{array}$ \\
\hline $\begin{array}{l}\text { Harris, McFarland, } \\
\text { Siebold, Aguilar, \& } \\
\text { Sarmiento }\end{array}$ & 07 & $\begin{array}{c}\text { Students } \\
3 \text { Native Amer. } \\
\text { Schools Districts } \\
900 \\
\text { Students }\end{array}$ & $\begin{array}{c}\text { Decreased Absenteeism, } \\
\text { Fighting }\end{array}$ & $\begin{array}{l}\text { Safe Schools Healthy } \\
\text { Students (SS/HS) }\end{array}$ & Quasi & $\begin{array}{c}\text { I, II \& } \\
\text { III }\end{array}$ & System & Quality \\
\hline
\end{tabular}




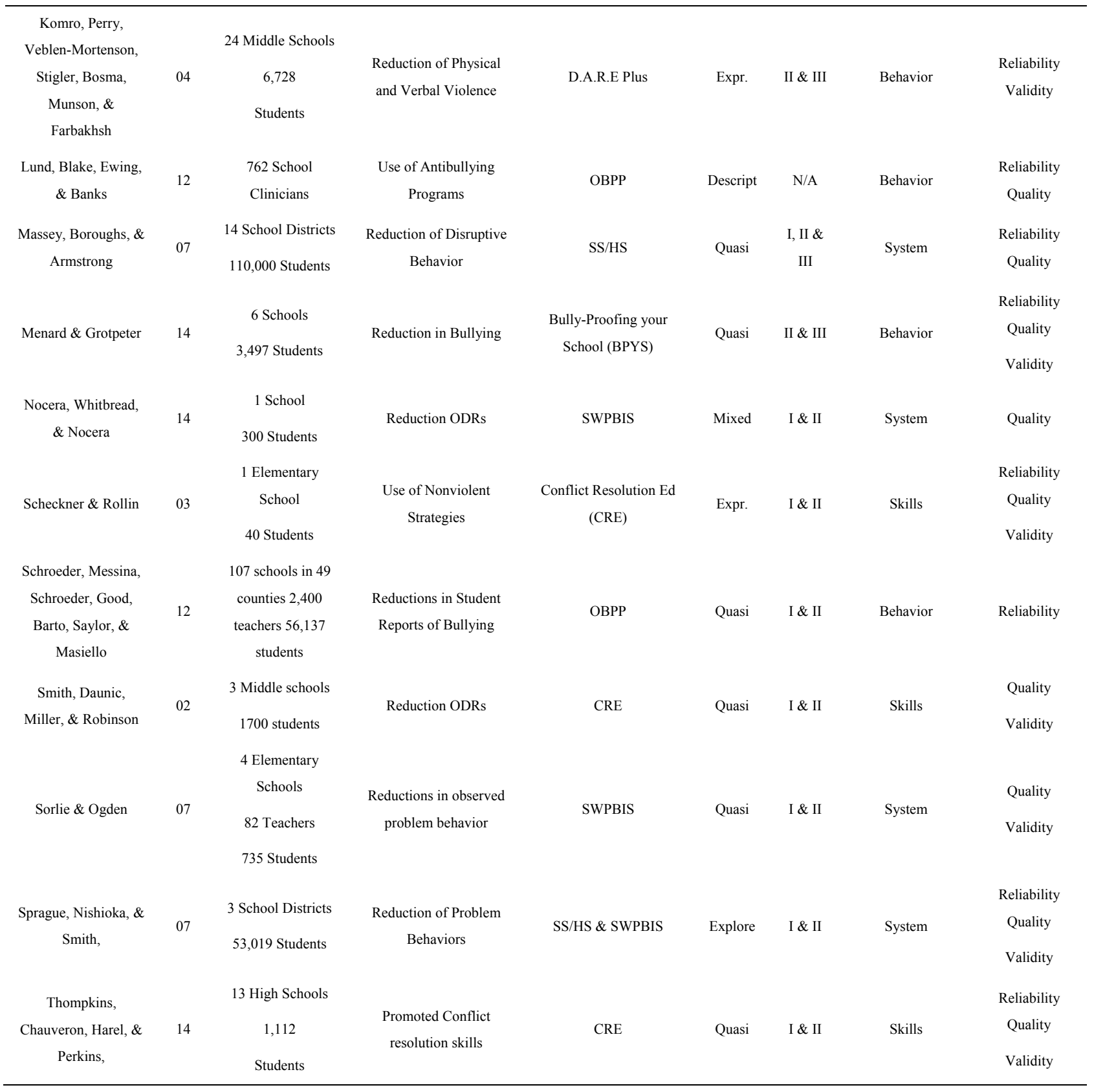

\section{Copyrights}

Copyright for this article is retained by the author(s), with first publication rights granted to the journal.

This is an open-access article distributed under the terms and conditions of the Creative Commons Attribution license (http://creativecommons.org/licenses/by/4.0/). 